\title{
Tiempo e historia: esbozos de la interpretación de Heidegger sobre la Segunda consideración intempestiva de Nietzsche
}

\section{Time and history: Outlines of Heidegger's Interpretation of Nietzsche's Second Untimely Meditation}

\author{
Sandra Lucía Montes Jiménez \\ Facultad de Filosofía y Letras \\ Universidad Nacional Autónoma de México | México \\ Contacto: sandramontes@filos.unam.mx
}

\section{Resumen}

Presentamos algunas directrices de la Interpretación de Heidegger sobre la Segunda consideración intempestiva de Nietzsche, tejiendo lazos entre la confrontación de Heidegger planteada en Ser y tiempo y este pensar de las "ventajas" e "inconvenientes" del saber histórico "para la vida", de la vida que demanda olvido y la vida que se recobra como recuerdo o "traer o retener en la memoria", o un "pensar-en" [Andenken] que se acuerda de su destino. Desde los planteamientos de ambos pensadores, buscamos entablar acuerdos y confrontaciones que nos conduzcan a pensar los "síntomas" de un exceso de "conocimiento histórico" que padece una época o una comunidad, y cuestionar las remisiones de la ausencia de una experiencia histórica o de un "olvido del ser", así como el desprendimiento del sentido originario de la temporalidad. En este sentido, nuestro objetivo central está en entablar un diálogo con la elucidación del tiempo originario que tanto Nietzsche como Heidegger desembozan para interrogar por un sentido del tiempo que se interna en la consideración histórica. Asimismo, buscamos traer a cuenta los motivos significativos de la obra de Nietzsche que impulsan a Heidegger a manifestar otra captación del fenómeno histórico que se desplegará como "meditación” del acaecer-apropiador de la historia misma. Para corresponder a la perspectiva de la 
pertenencia de la historia a la vida, revisaremos la confrontación con los temas arraigados y motrices de Ser y tiempo, esto, para demandar si, efectivamente, se entabla la discusión —en la obra de Nietzsche- entre la referencia del hombre como histórico y el animal como no-histórico. Además, si la "animalidad" puede ser llevada y asumida como base fundamental que delimita la esencia del hombre, como animal rational en la enmarcación de "un destino histórico occidental".

Palabras clave: vida, historia, tiempo, olvido, recuerdo, acaecer histórico

\begin{abstract}
We present some guidelines of Heidegger's interpretation of Nietzsche's second Untimely Meditation, weaving ties between Heidegger's confrontation in Being and Time and a mode of thought of the "advantages" and "disadvantages" of historical knowledge "for life", a life that demands forgetfulness and a life that is recovered as a memory, as a "bring or retention in memory" or a "think-in" [An-denken] who remembers his destiny. From the approaches of both thinkers, we seek agreements and confrontations that lead us to think of the "symptoms" of an excess of "historical knowledge" that suffers an era, a community, and to question the remissions of the absence of a historical experience or a "forgetfulness of being" — as a detachment from the original meaning of temporality. In this sense, our aim is to engage in a dialogue with the elucidation of original time that both Nietzsche and Heidegger fail to question for a sense of time that is internalized in historical consideration. We also seek to bring to mind the significant motives of Nietzsche's work that prompt Heidegger to manifest another uptake of the historical phenomenon that will be deployed as "meditation" of the event-appropriator of history itself. And to correspond to the perspective of the belonging of history to life, we suggest a confrontation-in Nietzsche's work-between man as historical and animal as nonhistorical. If "animality" can be carried and assumed as a fundamental basis that frames the essence of man, as a rational animal in within "a Western historical destination".
\end{abstract}

Keywords: life, history, time, forgetfulness, remembrance, historical event

\title{
Preliminares
}

Para Heidegger, el pensar de cada pensador alcanza a decir su pensamiento único a través del impulso de una experiencia fundamental (Heidegger, 2000), experiencia desde la cual se dispone un ritmo propio y una tonalidad fundamental que delimita la proveniencia y los confines de un pensar. 
En el pensar de Nietzsche, sostiene Heidegger, el destino más profundo de la historia occidental viene a decirse, viene a mostrarse en la experiencia de los signos de "lo que es ahora" (Heidegger, 2005: 119-121). Por eso, la intención yace en recobrar una experiencia de los síntomas y signos que dan asomo de una época carente de experiencia originaria. Así, en mirada previsora, Nietzsche reconocía el síntoma de la creciente e irreflexiva historiografía y la pérdida de historia originaria en la actual edad del mundo. Un signo alarmante pero desapercibido aparece, precisamente, como lo que es ahora (Heidegger, 2005).

De manera radical, Nietzsche diagnostica como signo epocal una sobresaturación historiográfica que ha determinado la interpretación de la historia de los "nuevos tiempos". Ante ello, Heidegger pone en juego una meditación histórica [geschichtliche Besinnung] que confronta el fundamento en el que reposa toda historiografía, denunciando, desde esta confrontación [Aus-einender-setzug], el padecimiento de la propia historia en su acaecer y en el proceder de su estudio a través del proceso de tecnificación que amenaza con dominarlo todo.

Apremiante resulta entonces reconocer la experiencia a la que alude Heidegger de la ausencia de historia, desde donde puede apreciarse que la historiografía cobra una superioridad y dominio sobre el ser humano de esta era tecnificada (Heidegger, 2008: 86). Así, se busca pensar la historia en una consideración que, en tanto busca penetrar en su sentido, se pone en el ejercicio de una meditación del acaecer apropiado y desapropiado de la historia (Heidegger, 1994: 33).

Es evidente para Heidegger que en el planteamiento de Nietzsche se establece la conexión entre "historicidad" y "temporalidad" como la conexión que sacudirá radicalmente, aunque de manera imperceptible, la concepción de la "animalidad del hombre". La perspectiva de Nietzsche denuncia la concepción que enmarca el desarrollo de la modernidad, dando cuenta de una concepción que abandera dos mil años de historia occidental. En la determinación del hombre como "animal racional", tanto el término de hombre como el de animalidad quedan indiferenciados, pero, a la vez, quedan determinados en razón de su olvido y de la posibilidad de "retener en memoria". De esta manera, la historia, que se caracteriza esencialmente por el resguardo de un registro de hechos, presupone un sentido de recuerdo o retención en memoria con vistas sólo a un pasado, lo cual será sometido a cuestión. 


\section{La confrontación: de la consideración a la meditación histórica}

En lo que sigue, quisiéramos presentar la interpretación de la Segunda consideración intempestiva de Nietzsche de Heidegger, ${ }^{1}$ explorando también algunos motivos centrales de la conceptualización de la meditación histórica ejecutada por él en los años 30. Estos motivos se concentran en ciertos enfoques dirigidos hacia el pensamiento de Nietzsche que impulsan significativamente el pensar histórico de Heidegger, uno de ellos al que aquí nos centraremos es: el análisis que enmarca el fenómeno [historial-historische] histórico-epocal que va a hacer destacar la diferencia que se abre en el acaecer-apropiador de la historia y el transcurrir historiográfico. Por un lado, lo que acaece y, por otro lado, lo que se registra.

El proceso histórico, en cuanto proceso epocal, se cierra ante el propio carácter vital del acaecer, pero, para Nietzsche, un sentido "propiamente histórico" tendría que pensarse desde un enfoque más profundo y elevado: como un poder inalterable que actúa imperceptiblemente sobre las fuerzas puras, como un poder no manifiesto de la historia misma, pero del que puede surgir el impulso natural de lo viviente (de lo verdadero). La naturaleza en cuanto vida no olvida, pero goza de un poder no-histórico, de un sentido que se le sustrae a la historia misma. Así se trate tan sólo de un acrecentamiento y consideración a la vida, señala Nietzsche, "la historia está al servicio de un poder no histórico" (Nietzsche, 1999: 51). Asimismo, desde la meditación rememorante, la historia guarda un sentido oculto, como señalará Heidegger en Aclaraciones a la poesía de Hölderlin.

Por su parte, podríamos decir que el hombre puede sentirse en posesión de la verdad, únicamente porque puede olvidar (como un modo de ocultamiento). El olvido será una referencia fundamental de Nietzsche, porque, como veremos, en el olvido se funda la posibilidad de una "toma de posición", y donde esta toma de posición rige la "perspectiva” que domina. Una perspectiva estimativa exige cierto grado de olvido al presuponer un sentido de conservación y aseguramiento de la vida, es decir, un sentido que garantice un crecimiento de vida mediante su propio aseguramiento, el cual va a demandar, primeramente, el olvido del carácter arriesgado y expuesto de la vida.

Este impulso de conservación que busca garantizar ante todo su propio aseguramiento, se revela con mayor énfasis cuando la vida se pone al servicio incon-

${ }^{1}$ Heidegger, M. (2009). Intérpretation de la 'Deuxième considération intempestive de Nietzsche' (Zur Auslegung Nietzsches II. unzeitgemässer Beotrachtung). Seminario de 1938/39 en Friburgo, aparece en 2003 como tomo 46 de la "Edición Integral", Gesamtausgabe (GA). (La traducción de la edición al francés es nuestra). 
dicional de la ejecución científica que regula, a su vez, toda consideración histórica. Y se presenta entonces que una toma de posición presupone un olvido necesario: la necesidad del ensalzamiento de una perspectiva de valor.

Ahora bien, vemos que este seminario invernal, que Heidegger dicta en la Universidad de Friburgo en los ańos de 1938/39, apunta a la vena central de los pensamientos de Nietzsche: la vida que demanda olvido. Ciertamente se pone en juego el trabajo de una consideración de la historia, pero, sólo a partir de cómo le es útil a la vida o qué inconvenientes guarda siempre aquella en relación con la vida en su capacidad de ser memoria y olvido a la vez. Y, en ese sentido, se pone de relieve preguntar cómo la historia responde al carácter vital de la propia vida.

De esta manera, Heidegger reconoce que la intención esencial del texto de Nietzsche está en despertar y salvar lo que la vida tiene de creador, en discrepancia con la perspectiva del biologicismo, que alcanza a enmarcar historiográficamente la marcha de la civilización occidental en el abanderamiento de la perspectiva del "ser vivo racional". Y, meditando desde el texto de Nietzsche, Heidegger cuestionará si es legítimo poner "a la vida" como efectividad fundamental en el sentido de una "biología de la civilización”, lo que pondrá en discusión el papel que juega ahora la perspectiva de un "biologicismo en el pensar". Y queda la pregunta si, efectivamente, el pensar de Nietzsche se salva o forma parte del discurso que él mismo cuestiona.

Ahora bien, veamos que la interpretación del ente como tal en tanto que vida se descubre en esta enmarcación, puesto que, fundamentalmente, preguntaríamos si se abre la discusión entre la referencia del hombre como ser histórico y el animal como no-histórico, esto, por su capacidad cada uno, decíamos, de olvidar y no poder recordar o traer a la memoria.

Heidegger proyecta al inicio de su seminario (Heidegger, 2003a; 2009) un triple objetivo: introducir a la formación de conceptos, lo que significará iniciar en el aprendizaje del pensar, es decir, el taller invisible que se abriga en el pensar de los pensadores, el taller como la búsqueda de la propia meditación que penetra en lo "no pensado" del pensar de un pensador fundacional, "anímico, creativo, invisible"; la lectura y la interpretación del tratado sobre la utilidad y los inconvenientes de la historia para la vida: aprehendiendo a pensar en compañía del pensador; finalmente, penetrar en la filosofía de Nietzsche: el hecho de que él sea "el último pensador de la filosofía occidental" y, en tanto que marca su final, cómo determina de manera decisiva su propio comienzo.

En dicho seminario, bosquejaremos entonces el problema del ser histórico y lo no histórico, y si viene permeado a partir del olvido y de la posibilidad del recuerdo o del retener en la memoria, siguiendo la interpretación que Heidegger lleva a cabo de la obra de Nietzsche de 1874 . Porque, ciertamente, será un hilo conductor 
para Heidegger pensar y llevar a una interpretación el texto de Nietzsche, como siguiendo su pensamiento fundamental para llevar a un análisis ontológico el despliegue de la historicidad [Geschichtlichkeit], enfatizando su carácter originario de acaecer [geschehen]. De esta forma, vemos primeramente que en este planteamiento sobre la consideración histórica, Heidegger inaugura — en radical profundidad y en constante diálogo con el pensar de Nietzsche- la pregunta por cómo se concibe la ciencia histórica y, cuál es el supuesto desde el que se rige el proceder científico que cuestiona y determina la historia [Historie].

Para Heidegger, la historia como ciencia tendría que partir originariamente del ente histórico, es decir, ser ella misma la apertura al ente histórico, y esto primordialmente por razón de su ser temporal. Esta referencia va a ser clave en las elucubraciones sobre la historicidad del propio Heidegger en tanto que se hace necesario y digno de preguntar en Ser y tiempo — concentradamente en $\$ 74$ y $\$ 76$ - por el ámbito originario del cuestionamiento de la historia, la cual hunde su raíz en la temporalidad, determinando así una "originariedad" en la consideración de la historia para la vida.

Por ello es que la triplicidad del saber histórico que reconoce osadamente Nietzsche, permite abrir la unidad originaria de la temporalidad que el mismo Heidegger tematiza hondamente en Ser y tiempo (Heidegger, 2003b). Así, se indica que el saber histórico refiere que: al éxtasis temporal del futuro se dirige la historia monumental; hacia el éxtasis del haber sido o pasado está direccionando la historia anticuaria; mientras que el presente se abre a partir de la historia crítica. En este sentido se hablará de que la temporalidad que sostiene la historia permite, por una parte, al advenir o futuro, la posibilidad del crear o intensificar la vida; por otra, conlleva al pasado a un proceso de conservación de la vida; y finalmente obliga al presente a liberar la propia vida. Intensificar, conservar y liberar a partir de las formas de la historia monumental, la anticuaria y la crítica, respectivamente.

Ahora bien, poco sabido es que Heidegger se confronta con el texto de Nietzsche desde los años de elaboración de Ser y tiempo, lo cual va a permear el propio desarrollo del pensador del ser y su preguntar fundamental por la temporalidad. Heidegger declara en esta obra que:

Nietzsche ha comprendido y dicho de un modo penetrante e inequívoco —en la segunda de sus Consideraciones intempestivas (1874) — lo esencial acerca de las "Ventajas e inconvenientes del saber histórico para la vida" [...] La clasificación de Nietzsche no está hecha al azar. El comienzo de su Segunda consideración permite conjeturar que él comprendía más de lo que él daba a conocer. (Heidegger, 2003b) 
Vemos entonces que Heidegger — a partir de su confrontación con el texto de Nietzsche- bosqueja el trazado de un proyecto sobre la génesis ontológica de la cuestión de la historia como ciencia, y el origen ontológico de esta estructura tripartita de concebir el proceso histórico. A partir de la apertura de la temporalidad originaria, la historicidad del Dasein asienta posibilidades propias que, fácticamente, se da a comprender como "proceso" del acaecer histórico: "Tan sólo la fáctica historicidad propia, en cuanto destino resuelto, puede abrir la historia que ya existió de tal manera que en la repetición la 'fuerza' de lo posible irrumpa en la existencia fáctica, es decir venga a ella en su futuridad" (Heidegger, 2003b: 407).

Heidegger ubica que de esta historicidad propia brota el saber histórico monumental al que refiere Nietzsche, es decir que: en cuanto el Dasein está entregado a su condición de arrojado, "está-siendo-sido" en una "apropiación repitente" de lo posible y en la cual es esbozada "la posibilidad de la conservación venerante de la existencia que ya existió”. Así, en cuanto monumental, el saber histórico propio es anticuarial. Y, en cuanto propio, este saber histórico anticuarial es necesariamente una crítica del "presente". Pues "en la unidad de futuro y el haber sido, el Dasein se temporiza como presente" (Heidegger, 2003b: 409). O sea que, en la unidad extática de la temporalidad, la existencia de un Dasein resuelto en su propio ser sí mismo congrega el tiempo en el acaecer originario. La existencia propia reúne el desgarre de la temporalidad en la apropiación de su historicidad.

Heidegger pregunta al propio texto de Nietzsche sobre las tres formas del saber histórico que corresponderían a los tres comportamientos de la vida humana, a saber: intensificar la vida guiada por el futuro; la conservación de la vida guiada por el pasado; y la liberación de la vida guiada por el presente. Y, a su vez, se pregunta de dónde proviene esta triplicidad y cómo forman parte de la vida, en cuanto intensificación, conservación y liberación; asimismo, por qué la vida misma tiene necesidad de la historia y cuál es la relación que guardan entre sí pasado, futuro y presente. De esta manera, a la pregunta por la historia, refiere que se trata de un "conocimiento del pasado" que está al servicio del futuro y del presente, y cuya constitución originaria estaría en responder a las necesidades de la vida. Pero Heidegger remite a que es la temporalidad la que funda y vuelve posible no sólo la historia en general, sino también la triplicidad de sus formas, así como la puesta en consideración de lo histórico mismo. Es decir, considerando primeramente el fondo temporal de sentido que posibilita algo así como una vuelta a su carácter aconteciente, y abriendo originariamente la vista a "lo posible", se despliegan las 
determinaciones propias de la existencia, elegidas o resueltas, conquistadas o recobradas, aunque esto sugiere tematizaciones ulteriores.

Sin embargo, lo que se está abriendo de manera extraordinaria en este preguntar, es la unidad originaria del tiempo como unidad ex-céntrica, ex-tática de la conjunción de futuro, haber-sido y presente. Y, la pregunta que permanece abierta es, según Heidegger, si la temporalidad misma impulsa necesariamente a la triplicidad de los comportamientos de la vida, misma que daría cuenta de la historia tal como la propone Nietzsche. Es decir, lo que vendrá a consolidarse —en las reflexiones posteriores - como la noticia de la "doctrina del eterno retorno" y del "umbral del instante".

Ahora bien, para la aclaración de la esencia de la historia, y su remisión originaria a la temporalidad, Heidegger propone introducir la diferencia entre lo que Nietzsche identifica como: conocimiento histórico e historia, y, de esta manera, poder determinar su relación. Al respecto, nos dice que:

1. El conocimiento histórico aporta, primeramente, un "conocimiento" en la representación de lo que "ha sido puesto ahí delante" (lo que da juego para la consideración historiográfica que se sustenta en el conocimiento del pasado y en el registro de hechos).

2. Lo acontecido se ubica como "objeto" posible del conocimiento histórico. La historia es concebida como un hecho o un registro de eventos. Pero la temporalidad adviene, originariamente, mientras "más el hombre es histórico y donde menos él tiene necesidad de historia” (Heidegger, 2009: 112).

3. La historia no es nunca mero "objeto" del conocimiento histórico [die Geschichte ist nicht "Gegenstand" der Historie, sondern Grund ihrer Moglichkeit], antes bien, la historia funda la posibilidad de dicho conocimiento: Es la historia, en tanto acontecimiento temporal - y no simplemente intratemporal como materiales y piezas monumentales-, el fundamento del conocimiento histórico. Es decir que el conocimiento histórico se experimenta sólo a partir de la historia [Historie aus Geschichte]. ${ }^{2}$

\footnotetext{
${ }^{2}$ Aquí traemos a cuenta la relación que se tiende entre tiempo e historia, así como la distinción de la Historia como historiografía [Historie] y la historia [Geschichte] que propicia lo histórico [geschichtlich] como el acontecer. Mantenemos en diálogo los análisis del seminario sobre La segunda intempestiva de Nietzsche y los parágrafos consagrados a analizar esta diferencia de Ser y tiempo. Cfr. Heidegger (2009: 113-118; 2003a: 104-111; 2003b: \$73-\$74).
} 
4. Sólo un ser aconteciente, es decir, propiamente temporal, puede ser comprendido como histórico [..."er est geschichtlich, weil er zeitlich ist"] (Heidegger, 2003: 104-111); dicho de otro modo, es aconteciente porque es temporal. Lo histórico [geschichtlich] sólo se concibe a partir de un ser temporal; el hombre como tal en tanto que histórico no puede ser uno que meramente "posee" una historia, sino que es histórico en tanto que la temporalidad puede determinar su esencia.

Entonces, la posibilidad de que algo así como un "sentido histórico" o la historicidad se explicite, viene fundada previamente por la posibilidad abierta del despliegue de la temporalidad: temporalidad propia del existente que es apertura a la propia verdad del ser. Pero, agravando la dificultad, Heidegger nos refiere que: "Mientras más la temporalidad adviene originariamente, más el hombre es historial [histórico, geschichtlich] y menos él tiene necesidad de historia" (Heidegger, 2009: 112). En otras palabras, el hombre no posee una historia, en todo caso es ella quien lo posee. El animal, en cambio, es sin-historia, y esto de una manera que no está anclado al pasado ni a un volver presente. El animal vive de manera no-histórica: en cada momento es plenamente lo que es.

Desde el "punto de vista del animal", éste "no tiene necesidad de olvidar". La vida es sin historia. Por ello, para Nietzsche la vida se recobra como una potencia ahistórica. Y, para Heidegger, sólo un ser histórico puede ser ahistórico. En ese sentido, la diferencia entre lo histórico y a-histórico de la historia no puede funcionar como un mero parámetro de diferenciación del hombre y del animal. Porque, como a su manera reconocerán ambos pensadores, la cuestión de la historia concierne sólo a la esencia del hombre, a "la vida humana" que puede recobrar su temporalidad:

1. Declara Nietzsche: "el animal no sabe lo que es ayer". El animal olvida en el sentido de que no puede retener en memoria, o lo que sería lo mismo decir: "no puede volver presente":

2. El animal no podría colocar frente a sí alguna cosa en tanto que presente: "él no sabe lo que es hoy" —el ahora, el presente-.

3. El animal olvida constantemente y, sin embargo, tiene "buena memoria". Lo que daría cuenta de su capacidad de ser "acaparado por el medio ambiente” y dar cuenta de un hábito, un aprendizaje y una destreza (el ave retiene en memoria el lugar de su nido, el petirrojo espera cada mańana el cielo abierto para realizar su danza, las aves migratorias vuelven a la misma región, el perro encuentra lo que enterró, el cuervo descubre lo que ocultó). 
4. El animal no olvida porque él no puede retener en memoria, en el sentido de volverse presente una cosa, re-presentársela como presente

5. En la perspectiva de la diferenciación de lo ahistórico y de lo histórico involucran a la historia como fijación y representación del pasado. Olvidar y recordar, ambas en tanto que modalidades diferentes remitidas al pasado. Donde se retiene un olvido y se olvida instintivamente, creadoramente.

El sentido de lo a-histórico para Nietzsche va a tener un sentido positivo porque va a delimitar, primero, lo propiamente histórico y la historia misma. Y, segundo, porque va a enfatizar el tipo de negación que lleva el prefijo "a": a-histórico, "sinhistoria" [Un-historische] es, en un sentido primordial, la vida; aquella que, en una expansión de vitalidad y plenitud se delimita como liberación. ¿Cómo? Al "no ser abatida por el peso de la historia”. Es en este sentido que para Nietzsche lo ahistórico es originario en tanto obedece primordialmente a la vida misma [ist das Unhistorische das Ursprüngliche, das Leben selbst] (Heidegger, 2003a: 99). En ese sentido, el animal obedece primordialmente a la vida y es originariamente ahistórico.

No obstante, la vida misma como tal, sufre una disminución cuando es apresada y presionada por la historia [Historie]. ¿Cuál historia? La que aparece entonces con la ratio, el pensamiento y el cálculo. De esta manera, en tanto que ahistórico es el carácter del animal, en el sentido de "no ser capaz en el fondo de historia", es también en el ámbito de la animalidad (humana) que lo a-histórico padece una disminución. La disminución del carácter de plenitud de la vida (específicamente humana) refiere a una depontenciación de su esencia, a una depotenciación de su plenitud a través de la mirada calculadora y productora de vivencias y de historia efectiva.

No obstante, la posibilidad de que el saber histórico en general tenga, en el lenguaje de Nietzsche, "ventajas" o "inconvenientes" "para la vida", se funda en que ésta es histórica en la raíz misma de su ser y que, por consiguiente, en el lenguaje de Heidegger, "en cuanto fácticamente existente, ya siempre se ha decidido por una historicidad propia o impropia" (Heidegger, 2003b: 409). Es en este planteamiento donde se despliegan las posibilidades de comprender la existencia del Dasein como histórica en cuanto que es tempórea, y es en esta temporeidad donde el Dasein logra temporizarse en la unidad extático-horizontal de sus éxtasis. En la extaticidad horizontal se juegan las posibilidades elegidas o resueltas del Dasein, y, a la vez, se juega lo que da la primera posibilidad de un retornar o volver a un "haber-sido" propio. Nos dice Heidegger: "El verdadero y "efectivo" haber-existido [del Dasein] será la posibilidad existentiva en la que fácticamente se ha determinado el destino individual, el destino colectivo y la historia del mundo" (Heidegger 2003b: 407). 
Ahora bien, la estructura de la verdad del saber histórico, según Heidegger, debe exponerse a partir del modo propio de la aperturidad (verdad) de la existencia histórica. Y, efectivamente, un "histórico estar vuelto hacia" es el que hace posible que el "haber-existido del Dasein" pueda recobrar su historicidad propia. Éste es el presupuesto (preteorético) que hace posible la "vuelta hacia un pasado". En este sentido, dice Heidegger que las actividades historiográficas no son lo que ponen en movimiento la ejecución histórica, sino que tan sólo presuponen este histórico estar vuelto hacia el "haber-sido" del Dasein. Señala Heidegger (2003b): "Ruinas", "monumentos" y "crónicas" son "material" posible para la concreta apertura del Dasein en su haber existido (406). Pero se convierten en material para el saber histórico en el ámbito del carácter "mundi-histórico" que les es respectivo. Sin embargo, la meditación del acaecer de la historia avanza más profundamente. Se adelanta hasta el "haber sido" como tal.

Pero, subrayemos esto con mayor detalle, enmarcando los lineamientos del análisis sobre la temporalidad a los que Heidegger apunta en su seminario:

1. La temporalidad [Zeitlichkeit] es precisamente el fundamento de la "constancia" del hombre que tiene como raíz un sentido histórico y es sostén de su historicidad [historial-Geschichtlikeit].

2. La temporalidad se distingue de la "intratemporalidad" [Innerzitigkeit].

3. La temporalidad es como "unidad de desgarramiento" [l'unité d'arrachement) Entrükungseinheit], una confrontación con el tiempo mismo (la posibilidad de retorno, de llegar a ser propio y del poder ser sí-mismo).

4. La temporalidad se distingue como la determinación más originaria de la esencia del hombre.

Así, vemos finalmente que, desde la analítica de la existencia se puede profundizar en la raíz temporal de la historicidad y en el modo propio e impropio de estar remitido a un "haber-sido", y donde nacimiento y muerte se conectan en la forma característica del Dasein. Así que, el análisis de la historicidad del Dasein intenta mostrar que este ente no es "tempóreo" porque "esté dentro de la historia", sino que, por el contrario, sólo existe y puede existir históricamente porque es tempóreo en el fondo de su ser (Heidegger, 2003b).

Heidegger va a evidenciar que la relación al presente y al futuro también queda abierta en la vista al pasado al que se dirige el estudio convencional de la historia. La historiografía encuadra los eventos históricos como pertenecientes al ámbito de lo pasado, y así quedan reducidos a meros objetos del proceso histórico, bajo el primado del conocimiento científico útil para la vida que toma la historia: 
Todo hombre o pueblo necesita, según sus metas, fuerzas y necesidades, un cierto conocimiento del pasado, bien sea como historia monumental, anticuaria o crítica, pero no como una manada de pensadores meramente limitados a la observación pura de la vida, ni como individuos hastiados a quienes únicamente puede satisfacer el saber y para los que el aumento de conocimiento es la meta en sí misma, sino siempre para el fin de la vida y, por tanto, bajo el dominio y conducción superior de tal objetivo. (Nietzsche, 1999: 67)

Puntualizando nuestro recorrido, podríamos decir que las líneas temáticas asociadas al texto de Nietzsche que se nos presentan desplegadas en el seminario de Heidegger sobre la Interpretación de la Segunda intempestiva..., a saber: la historia, la ciencia, el saber, y la verdad, conducen a la vida, es decir, al ente en total, al hombre, y a la toma de posición. Siguiendo estas líneas, podremos apreciar el síntoma creciente de la saturación de conocimiento histórico, el cual proviene de la instalación científica en la historia y del primado adquirido por la "ciencia" en historia (Heidegger, 2009: 125).

Para Heidegger, entonces la consideración de Nietzsche se vuelve intempestiva cuando se gira contra su presente para liberarse de él, para quebrantar el punto de partida de un presente delimitado por un conocimiento del pasado, comprendido como mera "suma" de adquisición de saberes. Entonces la cuestión decisiva permanece abierta, y está en saber cómo y por qué es determinada y llevada la relación del "presente viviente" al pasado y, finalmente, cómo y a partir de qué, la vida presente se aprecia ella misma. E intempestivamente, declara Nietzsche: "La voz del pasado es siempre la voz de un oráculo: sólo en cuanto obréis como arquitectos del futuro y conocedores del presente seréis capaces de comprenderla. [...] Ha llegado el momento de reconocer que sólo aquel que construye el futuro tiene derecho a juzgar el pasado" (Nietzsche, 2006: 91).

\section{Del estudio de la Historia desde la capacidad e incapacidad de retener en memoria}

Decíamos entonces que un síntoma que identifica Nietzsche, es que se padece de una "fiebre histórica" universal que no es reconocida como tal. El hombre se jacta de su humanidad ante el animal, pero anhela celosamente la dicha en la que éste anida, cual el animal preferiría vivir sin hastío ni dolor. No obstante, el animal no lo desea, simplemente olvida su olvido y esto le permite, a los ojos del hombre, vivir dichosamente, así como no poder olvidar lo que le es más conveniente; en 
cambio, el hombre no puede aprehender este olvido y vive desmesuradamente en un exceso de historia que allana la vida hasta su propia destrucción.

El hombre recuerda y a la vez busca olvidar, pues, el hombre, según Nietzsche, "se opone a la grande y creciente carga del pasado" y se venga de él. ${ }^{3}$ Qué nos indica esto: que el pasado, lo acontecido, el todo "fue", resulta lo más pesado, lo que deviene una carga, un peso difícil de llevar y soportar. Pero, acaso no es indicación de Nietzsche que "cuanto más fuertes sean las raíces de la naturaleza interior de un ser humano, tanto mayor es su capacidad de apropiarse o subyugar el pasado" y que, además, "una naturaleza poderosa e imperante [...] atraería y absorbería todo lo pasado y ajeno para transformarlo en sangre" (Nietzsche, 1999: 18).

Para Nietzsche, "la perspectiva histórica como la no histórica son igualmente necesarias para la salud de un individuo, pueblo o cultura", pero, habría que saber tanto olvidar como recordar en el momento justo, así como de intuir de una manera histórica cuando sea necesario, y así reconocer cuando no lo es: "Toda acción demanda olvido, tal como toda vida orgánica no sólo demanda luz sino también oscuridad" (Nietzsche, 1999: 16).

Pero, para caracterizar la esencia del olvido que Nietzsche supone en su Segunda Intempestiva, Heidegger nos da la indicación de permanecer atentos a aquello en lo que se funda el propio olvido, esto es: si el olvido es el "no retener en memoria”, entonces habrá que pensar el olvido desde la posibilidad de retención, de retener o reservar en memoria. Porque, en la posibilidad de recuerdo sucede una forma particular de retener, primeramente, el olvido como tal. En otros términos, se vuelve impensable la posibilidad de olvidar, ahí donde se cierra la posibilidad de guardar o contener en la memoria: La piedra no olvida - guarda memoria en su persistencia - y el animal olvida su olvido, pero, se guarda del olvido a la hora de anidar, migrar, desenterrar, guardando una memoria (Heidegger, 2009: 65).

No obstante, la posibilidad del olvido se halla abierta gracias a que se puede retener en memoria. Retener en memoria es la posibilidad que viene de la mano con la posibilidad de olvidar. Desde esta perspectiva, es posible hacerse la pregunta por la historia como un resguardo de una remisión directa con un pasado, con

${ }^{3}$ Recordemos el planteamiento de la "aversión del pasado" que se experimenta como "venganza". Heidegger explora una esencia de la temporalidad en los planteamientos del Zaratustra de Nietzsche. Nietzsche sitúa, frente al "espíritu de venganza" — que antepone un conocimiento del pasado y una aversión contra todo "fue" - el "umbral del instante"; el ámbito temporal desde el que se concibe la potencia histórica. La conjunción del tiempo desgarrado, libera y busca intensificar y conservar la vida. $\mathrm{El}$ instante abre la unidad originaria del tiempo como la relación de advenir-siendo-sido (Heidegger, 1994: 75-93). 
un "fue", o con un haber sido. Porque, si de memoria es de lo que carecemos, si predomina una incapacidad de retener, cómo entonces son dadas las posibilidades de poder recordar lo acontecido, de ofrecer una ojeada por anticipado al advenir, de poder pre-venir, pro-yectar, o anticipar. La perspectiva liberadora que aquí está en juego es que, recordando y proyectando un haber-sido originario, se inauguran otras posibilidades futuras. Y, no obstante, señala Nietzsche: "Un hombre carente de la fuerza del olvido, condenado a verlo todo como un devenir [...], viendo todas las cosas disolviéndose en un flujo de puntos en movimiento, se perdería a sí mismo en la corriente del incesante devenir. No se atrevería ni a mover un dedo" (Nietzsche, 2006: 16).

Nietzsche considera peligrosa y enemiga de la vida la sobresaturación histórica de una época (Nietzsche, 1999: 76); él lo explaya en cinco aspectos. Así que, siguiendo estas cinco perspectivas de la sección V del seminario, Heidegger desentraña la conexión de la Segunda consideración intempestiva entre la interpretación occidental moderna del hombre como animal rationaly lo que deviene como la concepción moderna de sujeto. De esta manera, Heidegger aborda esta cuestión de la nocividad de la historia para su época donde, según esto, la época está saturada de historia; esta sobresaturación de historia proviene de la dominación exclusiva y ejercida por la historiografía, porque se vuelven palpables para la vida los inconvenientes de sus efectos, y, a su vez, esta dominación procede de un poder autónomo incondicionado del mismo proceder de la historia como conocimiento, es decir, como ciencia o como producción técnica de historia. Pero, ¿qué sucedió aquí? Pues que "el ser humano ya no fue capaz de ser tan originariamente histórico para establecer el límite y la meta a la historiografía" (Heidegger, 2008: 86). Lo cual hace ver el modo metafísico de la historia moderna que se rige como: "voluntad incondicionada". Es decir, donde la incondicionalidad de la racionalidad del animal y la historiografía del acaecer parece no contener límites.

No obstante, no se concluye del texto de Nietzsche que los "inconvenientes" y lo "nocivo" de la historia venga a partir de su carácter científico y que por ello habría que promover una historia no científica o que la ciencia tenga que ser modificada sin más. En todo caso, habría de entenderse que el fundamento y la esencia de lo nocivo de la historia reside más bien en que la vida, la vida presente, a la que la historia responde, sea juzgada "miserable y vacía, sin reparos y sin objetivo". Lo cual va a poner en juego un planteamiento en torno a ese fenómeno que determina a la época de los nuevos tiempos: el nihilismo.

Ahora veamos brevemente en qué consiste cada una estas cinco perspectivas centrales que plantea Nietzsche en su Consideración intempestiva. En primer lugar, Nietzsche diagnostica en la modernidad una personalidad debilitada desde sus 
raíces y en la apropiación de un sentido histórico. Implícitamente lo dice: "cuanto más fuerte sean las raíces de la naturaleza interior de un ser humano, tanto mayor es su capacidad de apropiarse o de subyugar el pasado" (Nietzsche, 2006: 17). Hoy las raíces se muestran débiles, y somos poco capaces de apropiarnos de nuestra historia originaria. Ante ello, la posesión de conocimientos historiográficos reemplaza la ausencia de experiencia histórica. En segundo lugar, la ilusión de poseer una justicia superior: "Hemos de preguntar si el hombre moderno, alegando su 'objetividad' histórica, tiene derecho a jactarse de su fuerza y su justicia ante los hombres de otras épocas" (Nietzsche, 2006: 75). En tercer lugar, la destrucción de los instintos que obstaculiza la maduración del individuo tanto como la del pueblo o la unidad de una comunidad: "Cuando detrás del impulso histórico no impera un impulso constructivo, cuando no se destruye y se desescombra para que un futuro, que ya vive en la esperanza, pueda edificarse sobre el suelo despejado, cuando la justicia impera cual un fin propio, el instinto creador se encoge y es despojado de todo coraje" (Nietzsche, 2006: 92-93). Hoy, las posibilidades fundacionales de una cultura tradicional arraigada carecen de impulso, son escasas; falta la disposición como recordaría Heidegger: somos desde hace tiempo, sin disposición. En cuarto lugar, la aparición de la consciencia de ser fruto tardio y mero epígono en la vejez de la humanidad: "A nosotros, los rezagados, los últimos y pálidos retońos de las generaciones alegres y potentes [...] a esta vejez corresponde ahora una actividad de ancianos que consiste en mirar hacia atrás, resumir lo acaecido, hacer evaluaciones y buscar consuelo en el pasado recurriendo a la memoria; en una palabra: ejercer la cultura histórica" (Nietzsche, 2006: 105-106). Pero sólo como observadores analíticos o "críticos". En quinto y último lugar, la sobrevenida de una tonalidad irónica que adopta la actitud cínica, la cual conduce a una época referida a una "deliberada practicidad egoísta que termina por paralizar y, finalmente, destruir las fuerzas vitales" (Nietzsche, 2006: 64). Se trata de la actitud de un cinismo que busca justificar la marcha entera de la historia: "todo tuvo exactamente que ocurrir como justo es ahora y de ningún modo podría haber sido el hombre diferente a como ya es" (Nietzsche, 1999: 115). La necesidad de determinar un destino que se establece para justificar lo acaecido, como la necesidad de justificar el presente.

Pensada más originariamente, la cuestión de la historia y de su relación al hombre puede conducir a una meditación donde toda interpretación del hombre en la perspectiva de la "vida" y de la "animalidad" se encuentre sacudida y puesta ampliamente en cuestión.

A manera de recapitulación, echemos una ojeada al recorrido que hemos dispuesto. La palabra fundamental para Nietzsche en todas sus consideraciones es: "la 
vida". Y, en un sentido amplio va a designar tanto el ente en total como su manera de ser; y, en un sentido reducido también va a designar la "vida humana" o simplemente el hombre en su ser-hombre como sujeto o "corona de la creación". Ahora bien, se ha puesto de relieve que el hombre es la toma de posición o el criterio para preguntar por los inconvenientes o utilidad de la historia y, esto, en tanto que el hombre aparece como el ser propiamente histórico. No obstante, lo ahistórico también se ha puesto en juego de manera predominante en la vida humana. Aparentemente, la caracterización de lo histórico y el primado de lo a-histórico configuran un "antagonismo" que constituye al propio ser del hombre. Pero Heidegger nos ayuda a entender este antagonismo, aludiendo que se trata más claramente de una copertenencia. La unidad de esta copertenencia, de lo histórico y de lo ahistórico, nos arroja una luz sobre la esencia del hombre que aquí se pone en juego. La unidad de esta copertenencia tendrá que entenderse más osadamente como la pura diferenciación. Lo histórico que configura la existencia y lo ahistórico que la sostiene y fundamenta.

Ahora bien, esta diferenciación de lo histórico y ahistórico ha sido abierta a partir de la distinción entre olvido y recuerdo: el olvido constante que pertenece singularmente al animal y su necesidad o capacidad de recordar. Heidegger pone de relieve la necesidad de que la Consideración tome su impulso del animal, porque es ahí donde se abre la diferenciación entre el hombre y el animal, una demarcación que ha determinado un destino histórico occidental: "Es el evento que ha hecho que el hombre occidental se determine él mismo desde hace ya dos milenios como animal" (Heidegger, 2009: 36). La animalidad es puesta como el fundamento que ha delimitado la esencia del hombre. Y, remarca Heidegger: no es que el hombre se haya puesto simplemente sobre el mismo plano del animal, sino que, de manera decisiva "la animalidad es colocada, a título de dominio genérico, sobre la base en la cual se efectúa la particularización de la esencia del hombre" (Heidegger, 2009: 39).

De esta manera, Nietzsche, en su Consideración intempestiva, abre la delimitación esencial de la historia, es decir, la delimitación esencial del hombre frente al animal, lo cual va a significar que abre el cuestionamiento de aquella determinación de la tradición occidental que ha concebido al hombre como una animalidad "no fijada". Para Heidegger, plantear esta cuestión significa abrir la posibilidad y la necesidad de determinar la esencia del hombre de un modo más originario. Lo decisivo es que la cuestión de la temporalidad, como fondo que vuelve posible la historia en general, no recaiga sólo en la localidad del hombre, sino que sea orientada de otra manera y apunte originariamente a la relación del hombre con el ser, es decir, lo que da apertura a "la meditación sobre la instancia en la verdad del ser" [die Besin- 
nung auf der Inständigkeit in der Wahrheit des Seyns] (Heidegger, 2003a: 92; 2009: 110): "El grado y límite del olvido del pasado se determina por la fuerza de cada ser humano, pueblo y cultura: [...] aquella fuerza de crecer de sí mismo y de manera propia, de transformar lo pasado y desconocido y de incorporarlo (apropiarlo), sanar las heridas, recuperar lo perdido y recomponer las fuerzas quebrantadas" (Nietzsche, 2006: 17).

\section{Referencias bibliográficas}

Heidegger, Martin. (1994). Conferencias y artículos, (Eustaquio Barjau, Trad.). Barcelona: Ediciones del Serbal.

Heidegger, Martin. (2000). Nietzsche I, II., (Juan Luis Vermal, Trad.). Madrid: Ediciones Destino.

Heidegger, Martin. (2003a). Zur Auslegung von Nietzsches II. Unzeitgemässer Betrachtung. Francfort-sur-le-Main Vittorio Klostermann.

Heidegger, Martin. (2003b). Ser y tiempo, (Eduardo Rivera, Trad.). Madrid: Trotta. Heidegger, Martin. (2005). Àchevement de la métaphysique et poésie, (Adéline Froidecourt, Trad.). Paris: Éditions Gallimard.

Heidegger, Martin. (2008). Preguntas fundamentales de la filosofía. "Problemas" selectos de "lógica", (Ángel Xolocotzi, Trad.). Granada: Comares.

Heidegger, Martin. (2009). Interprétation de la Deuxième Considération Intempestive de Nietzsche, (Alain Boutot, Trad.). Paris: Éditions Gallimard.

Nietzsche, F. (1999). Sobre la utilidad y el perjuicio de la historia para la vida. II Intempestiva, [Germán Cano, ed.]. Madrid: Editorial Biblioteca Nueva.

Nietzsche, F. (2006). Segunda Consideración Intempestiva. Sobre la utilidad y los inconvenientes de la Historia para la vida. Buenos Aires: Libros del Zorzal. 